\title{
AC 2007-1021: THE AQUARIUM PROJECT: TEACHING ENGINEERING PRINCIPLES AND SUSTAINABILITY
}

\section{Kauser Jahan, Rowan University}

Kauser Jahan is a Professor of Civil and Environmental Engineering at Rowan University. She completed her Ph.D. studies in the Department of Civil and Environmental Engineering at the University of Minnesota, Minneapolis in 1993. After completion of her graduate studies, she worked as an environmental engineer for the Nevada Division of Environmental Protection (NDEP). Her research interests include bioremediation of contaminated groundwater and soils; the fate and transport of pollutants in the environment; and applied microbiology in environmental engineering. She is also actively involved in encouraging women to the engineering profession. 


\section{ENGINEERING CLINICS FOR TEACHERS}

\section{Introduction}

There is a growing realization among engineering faculty that a new vision for the education of engineers needs to evolve to keep this country at the forefront of technology. Science and engineering are essential partners in paving the way for America's future through discovery, learning and innovation ${ }^{1-2}$.

A recent report ${ }^{3}$ indicates that the United States lags behind the world in technological innovation because of its poor performance in teaching math and science. This eliminates many of the best and brightest schoolchildren from the ranks of future scientists and engineers. Many students who do undertake science and engineering studies in college are unprepared and drop out in frustration, while other potentially capable students never consider these subjects in the first place. In both cases, precious human and institutional resources are squandered.

Enhanced engineering education in our K-12 classrooms can provide students at an earlier age with a more specific understanding of what a technical career entails. We must encourage teachers to assume a more active role not only in the implementation/delivery of the educational experience for the student, but also in the innovation and continuous improvement necessary for engineering education to meet these challenges.

\section{The ECT Program}

This ECT (Engineering Clinics for Teachers) Program is a partnership between Rowan University's Colleges of Engineering and Education to provide an Engineering Clinic experience for middle school teachers and guidance counselors. Modeled after the unique Rowan Engineering Clinics $^{4-5}$, it utilizes real world problem solving via simple cost effective activities. The overall objectives of the program are to:

- Provide exposure to engineering careers and make engineering more relevant to middle school educators,

- Ensure that teachers are academically prepared to successfully integrate engineering content into their existing curriculum,

- Support teachers and students in exploring and understanding engineering content in K-12 education through professional development activities, and

- Serve as a national model for other undergraduate institutions in integrating engineering content in K-12 education.

This is the first university initiative to integrate engineering content in the middle school curriculum and train teachers regarding engineering concepts as well as the identification of students with potential to become engineers. The ECT program is being funded by a generous grant from the Martinson Foundation. 


\section{Rowan's Engineering Clinic Program}

The ECT program activities reflect our Engineering Clinic activities that are offered to our incoming freshman engineering students. As such a brief overview of the Rowan engineering clinics is provided below:

Rowan's engineering programs include hands-on, team-oriented laboratory and real world experiences with a strong interdisciplinary component. All engineering students take eight semesters of required Engineering Clinic Courses ${ }^{4-5}$ a unique component of the engineering program. Key clinic features include:

- Creating inter- and multi-disciplinary experiences through collaborative teamwork,

- Stressing innovation and total quality management (TQM) as the necessary framework for solving complex problems,

- Incorporating state-of-the-art technologies throughout the curricula, and

- Creating continuous opportunities for stronger communication skills.

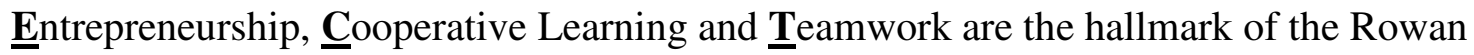
Engineering Clinics.

Table 1 indicates an overview of the engineering clinic content in the 8-semester engineering clinic sequence. As shown in the table, each clinic course has a specific theme although the main theme of engineering design pervades throughout.

Table 1: Overview of course content in the 8-semester Engineering Clinic sequence

\begin{tabular}{lll}
\hline Year & Engineering Clinic Theme (Fall) & Engineering Clinic Theme (Spring) \\
\hline Freshman & Engineering Measurements & $\begin{array}{l}\text { Competitive Assessment Laboratory } \\
\text { Product Dissection }\end{array}$ \\
\hline Sophomore & $\begin{array}{l}\text { 16-Week Multidisciplinary Design } \\
\text { Project—Composition \& Rhetoric }\end{array}$ & $\begin{array}{l}\text { 16-Week Multidisciplinary Design } \\
\text { Project—Public Speaking }\end{array}$ \\
\hline Junior & $\begin{array}{l}\text { Product/Process Development or } \\
\text { Research }\end{array}$ & $\begin{array}{l}\text { Product/Process Development or } \\
\text { Research }\end{array}$ \\
\hline Senior & \multicolumn{2}{c}{ Multidisciplinary Capstone Design/Research Project } \\
\hline
\end{tabular}

Freshman Clinics expose students to basic engineering skills including problem solving, teamwork fundamentals, engineering measurements and entrepreneurship. Students are introduced to a variety of activities relevant to engineering measurements ${ }^{5}$. This is followed in the second semester by intense study of engineering design through reverse engineering ("dissection") and competitive assessment of a consumer product ${ }^{6-8}$. Competitive assessment is the systematic testing of existing products for the purpose of improvement and comparison. Students are encouraged to develop innovative product improvement schemes. Past projects include studies of the following products or processes: electric toothbrush, soccer helmets, living aquarium, portable water filters, beer brewing, thermoelectric coolers, blood pressure cuffs, carbon monoxide detector and principles related to the human body. 


\section{Implementation of the ECT Program}

\section{Program Organization and Delivery}

The ECT project is a joint effort between the Colleges of Engineering and Education.

\section{Program Venue and Duration}

The ECT program is a 5-day summer residential workshop at Rowan University. The residential aspect provides opportunities for teachers and university faculty to form closer bonds as a learning community that works together on common problems. Teachers stay on campus at the residence hall with meals provided at the University dining hall. If participants have conflicts with staying overnight a non residential option is also provided to better serve the community.

\section{Target Population}

Math, Science, Technology, Social Sciences and English teachers and guidance counselors from middle schools are the major target population for this workshop. The Southern New Jersey school districts represent a diverse body of students and teachers with a wide range of socioeconomic status. We anticipate teacher participation from the six neighboring counties: Burlington, Gloucester, Camden, Cumberland, Atlantic and Salem.

\section{Recruitment and Selection}

Recruiting efforts include traditional methods such as mailings, flyers, brochures, electronic networking and visits to the school district offices to promote participation. A website ${ }^{9}$ is also maintained to disseminate relevant information. Recruitment goals include a diverse representation of teachers in terms of geographic distribution, specialization and level of interest. Teachers are provided with an honorarium and continuing education units (CEUs).

\section{Workshop Activities}

Teachers are divided into small teams to work on real-world problems involving engineering, mathematics and science. These real-world problems are derived directly from the current engineering clinics led by engineering faculty and incorporate hands-on activities typically developed for Rowan freshman engineering students. For example, teachers are taught how to design an efficient soda bottle rocket using their science and math skills. This exposes them to connect Newton's third law of motion to concepts in aerospace engineering and get their students excited about careers at NASA. A module on preparing lip gloss exposes them to chemical reactions in preparing cosmetics and to chemical engineering processing. A human body module teaches participants the similarities between the human body organs and many engineered systems. An aquarium is used to demonstrate the science and engineering that goes behind the design and maintenance of such a facility. A bridge building activity using paper and Jenga blocks introduce participants to structural engineering. All these modules are taught by engineering faculty. Appropriate handouts and problem assignments are also provided during these modules so that teachers can use these in their classrooms. Care is taken to make ensure that the experiment is cost effective and can be easily used in a classroom setting. This is extremely important as the local school districts are plagued with budgetary constraints and lack of well equipped science laboratories. Many educators are also reluctant to introduce time consuming activities that takes away from their state core standards. 
All modules selected are relevant to the course content directed by school districts. Communication skills are also a part of the workshop by integrating technical writing and presentation modules. The engineering faculty collaborate with the education faculty to ensure the relevance of the activities and to make the experience appealing to the teachers. Participating teachers are also provided with an opportunity to observe students participating in Rowan's Materials Science Institute or Attracting Women into Engineering workshops for high school and middle school students.

Another innovative aspect of the ECT program is the incorporation of reflective activities. K-12 educators have a tremendous challenge in educating our future generations. It is not uncommon for these educators to feel stress and anxiety that can eventually lead to burnout and poor job performance. Too often teachers are so caught up in the content and delivery of their programs that scant attention is paid to reflection on the how and why of what they are doing. Thus, time for reflection on the activities, attention to how one learns and the need for care of the self are included in the day-to-day schedules. Emphasis is placed on balancing the academic aspects of the clinic experiences with attention to mental and physical health. These activities include trips to the university recreation center, yoga classes, nature walks, journal reflections, laughter, meditation, and art classes and field trips.

\section{Assessment and Impact}

Assessment of the workshop is carried out via surveys during and after the duration of the workshop. Select visits are made to schools to watch teachers integrate and deliver the material provided to them during the ECT workshop. Teachers are invited to a fall and spring follow up meeting to discuss the impact of the workshop and the ease or difficulty in delivering the engineering clinic modules. This assessment provides key information in planning activities for future years. Successful teachers are invited back to participate as mentors in the next session.

\section{Summer 2006 ECT Workshop}

A total of seventeen middle school teachers participated in the ECT workshop. Math, Science, Technology and Special Education teachers were among the participants. A total of 11 schools were represented from 10 school districts. Participants arrived on Sunday June 25, 2006 to check into the university housing. A dinner with jazz music was provided as an icebreaker event. The project directors welcomed the participants and also discussed the scheduled activities for the workshop.

Clinic Modules: Four engineering clinics were included in the workshop. These clinics represented the four engineering disciplines at Rowan University namely Chemical, Civil and Environmental, Mechanical and Electrical and Computer Engineering.

The Bridge module allowed participants construct different types of bridges using Jenga blocks and a Computer software the Bridge Builder ${ }^{10}$ to design a truss bridge. Participants were presented with an individual Jenga block set for instructional purposes in their classrooms. Participants were also involved in discovering what makes a device or machine a 'robot'. They built a few robotic Lego ${ }^{\mathrm{TM}}$ vehicles ('cars') and programmed them to complete specific tasks. Fundamental skills and concepts in mechanical engineering, such as computer programming, 
gearing, structural stability, and sensors was discussed. The session culminated in a minicompetition in which teams of participants built a robot and competed in head-to-head competitions to achieve a given goal.
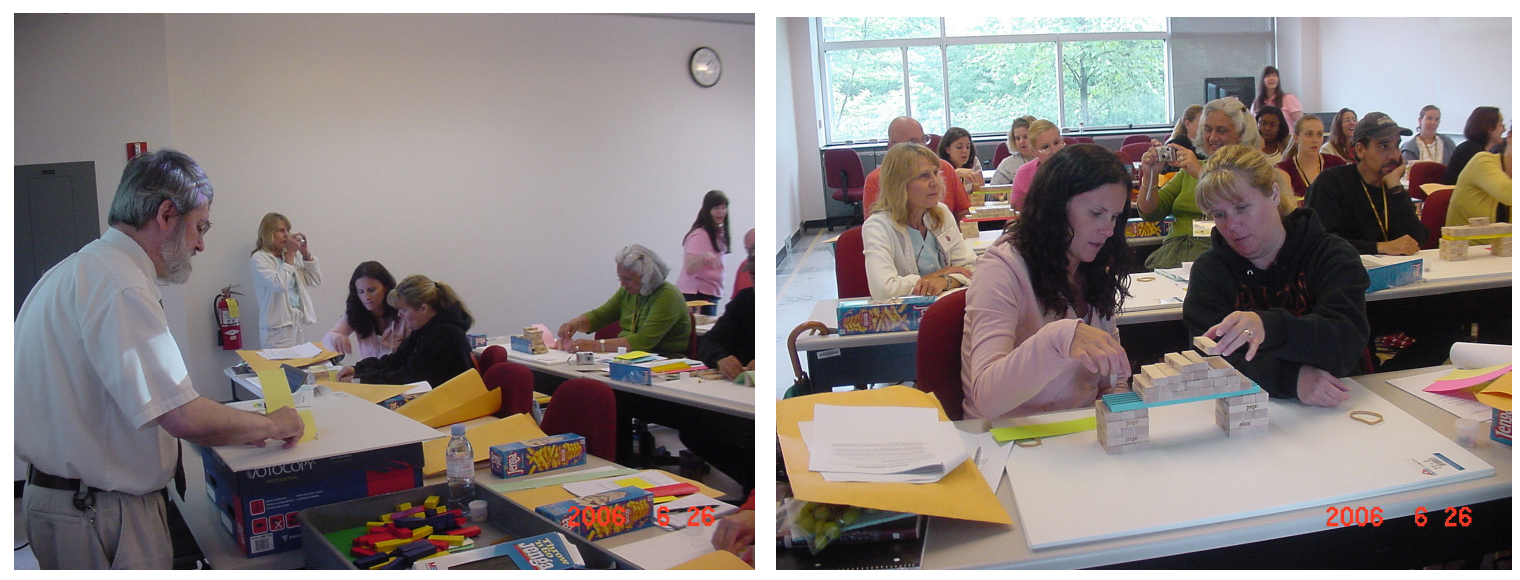

Figure 1: Teachers building bridges using Jenga ${ }^{\mathrm{TM}}$ Blocks
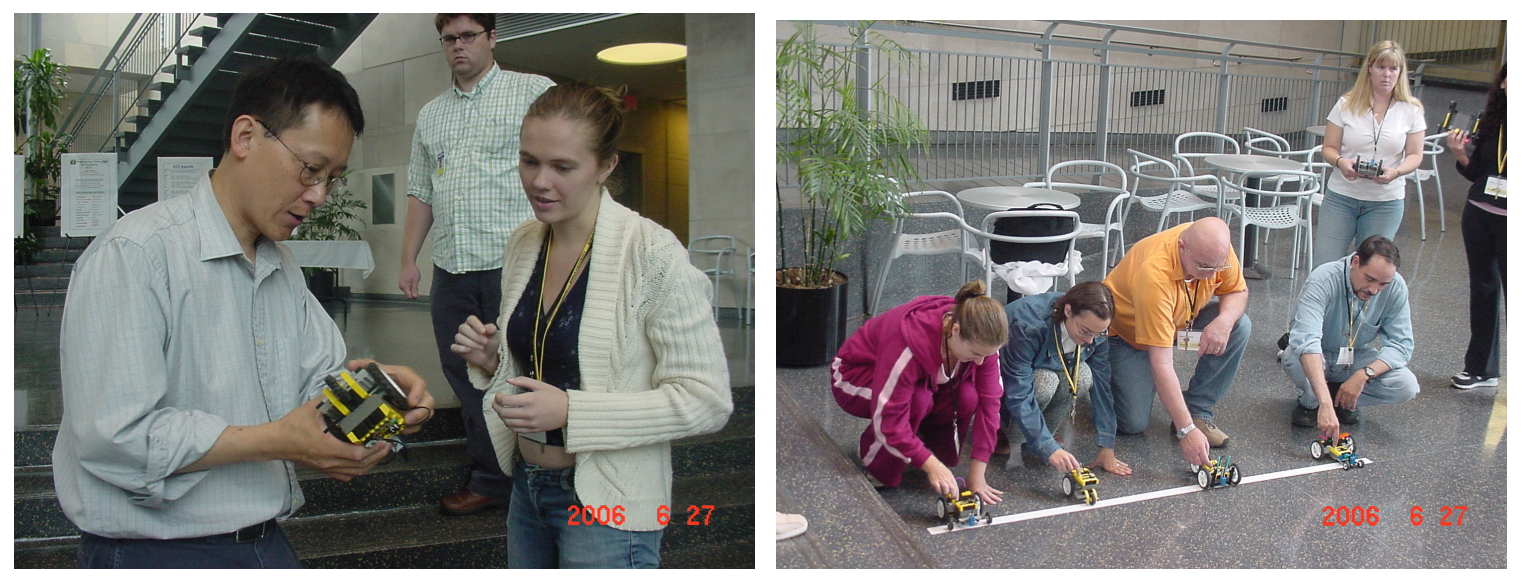

Figure 2: Teachers building Lego ${ }^{\mathrm{TM}}$ Robots

The "Hands on the Human Body" clinic module focused on comparison of the human body with engineered systems. When most people think of engineering, the human body usually is not the first thing that comes to mind, but the systems of the body can be used to demonstrate engineering principles from all of the major disciplines. Simple experiments using the human muscles were used to demonstrate the concepts of levers and force balances which are very common in Physics. Blood pressure monitors and the human heart were used to demonstrate concepts of hydrostatic pressure in a fluid flow system.

A circuits module that involved the construction of a circuit that not only generates a square wave (a train of logic zero and one pulses), but also turned the pulses into a four digit binary 
number that increments with each pulse. Then, the four digit binary number was "decoded" to light up the corresponding decimal on the seven-segment display.

Field Trip: Participants were taken to the New Jersey State Aquarium for a half day field trip. The objective of this field trip was to have participants identify the engineering behind the operation, maintenance and design of an aquarium. An aquarium is an exquisite combination of interacting systems which can be analyzed using multidisciplinary engineering and scientific principles. Children typically have personal aquariums for their pet fishes and visit some large aquarium as part of a school field trip or as part of their family outing. Movies such as DisneyPixar's "Finding Nemo", Epcot's Living Seas also make tremendous impact on a young audience. While these activities apparently raise the knowledge base in terms of nature and the environment, children seldom make a connection to the engineering principles playing out in the maintenance of a natural, commercial or personal aquarium.

Teachers were specifically instructed to first reflect on topics that they would have identified without knowing anything about engineering. Then they were asked to reflect on how the aquarium field trip could be used to expose students to engineering.

Topics that are typically exposed to students during such a trip included species, biodiversity, pollution prevention of marine environments, predator organisms, ecosystems etc.

Teachers recognized that maintenance of water quality and water treatment in aquariums is a major contribution of engineering. They further identified that gas transfer was a major mechanism for maintaining correct dissolved oxygen concentration in the water. Pumping systems, design of the shark tunnel and the 4-D children's ride also stimulated discussion on connecting engineering to a fun field trip.

Art Activity: The art activity was offered by a local high school teacher to allow the teachers to end their long day on a creative note. Teachers were taught a special technique of using a grid on an existing picture and preparing their own paintings. This exercise was also connected to engineering via simple examples such as the following:

a) the role of engineers in developing materials such as paints, colors, dyes etc.

b) the legacy of Leonardo Da Vinci to engineering

c) the infusion of grids and the concepts of scaling.

Assessment: Data is available from the summer of 2006 when the first ECT workshop was offered. Daily surveys were conducted to gauge the quality of the workshop activities. Participants were also encouraged to provide comments about every activity. Survey results are being used to improve the 2007 ECT workshop. The overall results and comments were very encouraging.

A typical survey used daily is presented on the following page. 
ENGINEERING CLINICS FOR TACHERS SURVEY

\begin{tabular}{|ll|}
\hline 4=Excellent & 1=Needs Improvement \\
\hline
\end{tabular}

Opening Ceremony
1
2

3

4

\begin{tabular}{|l|l|l|l|l|}
\hline Content Of Presentation & & & & \\
\hline Quality Of Presentation & & & & \\
\hline $\begin{array}{l}\text { Organization Of } \\
\text { Presentation }\end{array}$ & & & & \\
\hline $\begin{array}{l}\text { Overall Quality Of } \\
\text { Session }\end{array}$ & & & & \\
\hline
\end{tabular}

Comments:

Clinic - Hands on The Human Body

\begin{tabular}{|l|l|l|l|l|}
\multicolumn{2}{l}{1} & \multicolumn{1}{c}{3} & \\
\hline Content Of Presentation & & & & \\
\hline Quality Of Presentation & & & & \\
\hline Organization Of & & & & \\
Presentation & & & & \\
\hline Overall Quality Of & & & & \\
Session & & & & \\
\hline
\end{tabular}

Comments:

Art Activity -

1

2

3

4

\begin{tabular}{|l|l|l|l|l|}
\hline Content Of Presentation & & & & \\
\hline Quality Of Presentation & & & & \\
\hline $\begin{array}{l}\text { Organization Of } \\
\text { Presentation }\end{array}$ & & & & \\
\hline Overall Quality Of & & & & \\
Session & & & & \\
\hline
\end{tabular}

Comments:

Did you have a chance to verbally participate? Yes

No

Your assessment of the workshop materials that were used today:

Excellent Satisfactory Needs Improvement

Did you learn something today that you will use in your job to improve classroom instruction?

_ Yes__ No

If you answered Yes, Please very briefly describe what you will use. 
Select assessment results for the workshop are indicated below:

\begin{tabular}{|c|c|c|c|c|}
\hline \multirow{2}{*}{\multicolumn{5}{|c|}{ Keynote Address }} \\
\hline & & & & \\
\hline $\begin{array}{l}\text { CONTENT OF } \\
\text { PRESENTATION }\end{array}$ & & & $\begin{array}{l}3 \text { or } \\
27 \%\end{array}$ & $\begin{array}{l}8 \text { or } \\
73 \%\end{array}$ \\
\hline $\begin{array}{l}\text { QUALITY OF } \\
\text { PRESENTATION }\end{array}$ & & & 1 or $9 \%$ & $\begin{array}{l}10 \text { or } \\
91 \%\end{array}$ \\
\hline $\begin{array}{l}\text { ORGANIZATION OF } \\
\text { PRESENTATION }\end{array}$ & & & 1 or $9 \%$ & $\begin{array}{c}10 \text { or } \\
91 \%\end{array}$ \\
\hline $\begin{array}{l}\text { OVERALL QUALITY OF } \\
\text { SESSION }\end{array}$ & & & 1 or $9 \%$ & $\begin{array}{l}10 \text { or } \\
91 \%\end{array}$ \\
\hline
\end{tabular}

Hands on the Human Body

\begin{tabular}{|l|c|l|c|c|}
\hline CONTENT OF & 2 or & & 4 or & 5 or \\
PRESENTATION & $18 \%$ & & $36 \%$ & $45 \%$ \\
\hline QUALITY OF & 2 or & & 4 or & 5 or \\
PRESENTATION & $18 \%$ & & $36 \%$ & $45 \%$ \\
\hline ORGANIZATION OF & 2 or & & 4 or & 5 or \\
PRESENTATION & $18 \%$ & & $36 \%$ & $45 \%$ \\
\hline OVERALL QUALITY OF & 2 or & & 4 or & 5 or \\
SESSION & $18 \%$ & & $36 \%$ & $45 \%$ \\
\hline
\end{tabular}

Bridges

\begin{tabular}{|l|l|l|l|l|}
\hline CONTENT OF & & & & 11 or \\
PRESENTATION & & & & $100 \%$ \\
\hline QUALITY OF & & & & 11 or \\
PRESENTATION & & & & $100 \%$ \\
\hline ORGANIZATION OF & & & & 11 or \\
PRESENTATION & & & & $100 \%$ \\
\hline OVERALL QUALITY OF & & & & 11 or \\
SESSION & & & & $100 \%$ \\
\hline
\end{tabular}

Art Activity
\begin{tabular}{|l|l|l|l|l|}
\hline CONTENT OF & & & & $\begin{array}{c}11 \text { or } \\
\text { PRESENTATION }\end{array}$ \\
\hline QUALITY OF & & & $100 \%$ \\
PRESENTATION & & & & 11 or \\
\hline ORGANIZATION OF & & & & $100 \%$ \\
PRESENTATION & & & & 11 or \\
\hline OVERALL QUALITY OF & & & & 11 or \\
SESSION & & & & $100 \%$ \\
\hline
\end{tabular}


Overall the survey results indicated the following

a) The keynote presentation was excellent and introduced participants to the need for K-12 educators to introduce engineering in their classes.

b) The engineering clinics exposed participants to various engineering disciplines. The Bridge and Robot modules were well received. Some participants felt that the circuits and hands on the human body modules were difficult for the middle school level.

c) The overall quality of the workshop was excellent and of great use to the teachers.

d) Participants indicated that the reflective activities were useful but at times too lengthy.

e) All participants indicated that the workshop helped them connect their coursework to engineering.

f) All participants indicated daily that they had learned something to connect engineering to their existing course material.

Verbatim participant responses to the reflective activities are presented below:

"The reflective sessions were better than I expected. The value of sharing experiences, ideas, thoughts and questions with other teachers cannot be overstated. I also appreciated questions that made me think about my own teaching in ways that I hadn't before."

"I have managed to enrich my teaching practice through these workshops by realizing (through the art project) the frustration that students feel coming into my classroom day in and day out. My head and heart can now relate to one another."

The ECT 2006 participants will be attending a follow-up workshop in April of 2007 to present their individual efforts in the classroom to expose engineering to their students. Some visits by engineering faculty to select schools are also in preparation for the spring of 2007. These visits are designed to observe and help school teachers with an engineering activity.

\section{Conclusions}

The Engineering Clinics for Teachers workshop at Rowan University was very successful in its first year. This is evident from the workshop evaluations and the level of participation. Teachers indicated that identifying simple inexpensive hands on projects that complement their current science and math curriculum is a simple way of connecting engineering to math and science course content. The workshop also allows engineering and education faculty to collaboratively work on training the teachers. This is a more realistic way of teacher preparation than having engineering educators offer such workshops alone. 


\section{References:}

[1] Connant, J.B. (1959) The American High School, McGraw-Hill, New York.

[2] http://www.nsf.gov

[3] http://www.engineeringk12.org/Engineering in the K-12 Classroom.pdf

[4] Jahan, K., Marchese, A. J., Hesketh, R. P., Slater, C. S, Schmalzel, J. L., Chandrupatla, T. R. and Dusseau, R. A. (1997), "The Rowan Engineering Program : Preparing Students for the Future Job Market", Proceedings of the 1997 Zone I Fall Meeting, Wilmington, Delaware, October 1997.

[5] Jahan, K., Marchese, A. J., Hesketh, R. P., Slater, C. S, Schmalzel, J. L., Chandrupatla, T. R. and Dusseau, R. A. (1998), "Engineering Measurements and Instrumentation for a Freshman Class", Proceedings of the 1998 ASEE Annual Conference, Seattle, Washington, June 1998.

[6] Farrell, S., Newell, J. A. and Savelski, M. J., Introducing Chemical Engineering Students to Product Design through the Investigation of Commercial Beer, Accepted for Publication in CEE, October 2001.

[7] Jahan, K. "Water treatment in reverse", Proceedings of the 1999 Annual Conference of ASEE, Charlotte, North Carolina, June 1999.

[8] Jahan, K., Tang, Gina and Riddell, William (2005), Teaching Engineering Principles Using an Aquarium, Proceedings of the Mid-Atlantic ASEE Spring Conference, Teaneck, New Jersey.

[9] http://users.rowan.edu/\%7Ejahan/ECT_06_08/Ect/index.htm 